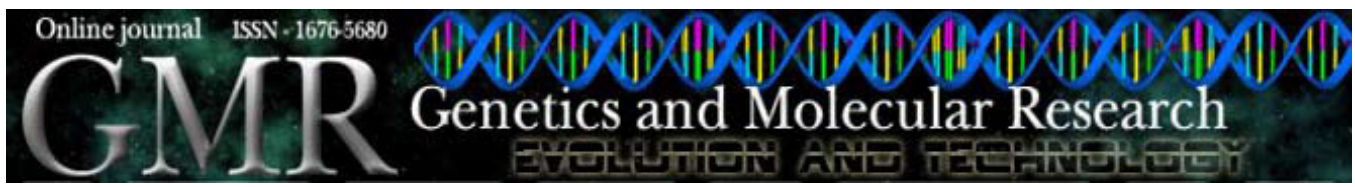

\title{
Remarkably low genetic variation but high population differentiation in the climbing perch, Anabas testudineus (Anabantidae), based on the mtDNA control region
}

\author{
A.F.J. Jamsari' ${ }^{1}$ Z.A. Muchlisin ${ }^{1,3}$, M. Musri ${ }^{4}$ and M.N. Siti Azizah ${ }^{1,2}$ \\ ${ }^{1}$ School of Biological Sciences, Universiti Sains Malaysia, Minden, \\ Penang, Malaysia \\ ${ }^{2}$ Centre for Marine and Coastal Studies, Universiti Sains Malaysia, Minden, \\ Penang, Malaysia \\ ${ }^{3}$ Department of Aquaculture, Coordinator of Fishery and Marine Sciences, \\ Syiah Kuala University, Banda Aceh, Indonesia \\ ${ }^{4}$ Department of Marine Sciences, Coordinator of Fishery and Marine \\ Sciences, Syiah Kuala University, Banda Aceh, Indonesia \\ Corresponding author: M.N. Siti Azizah \\ E-mail: sazizah@usm.my
}

Genet. Mol. Res. 9 (3): 1836-1843 (2010)

Received June 24, 2010

Accepted July 18, 2010

Published September 14, 2010

DOI 10.4238/vol9-3gmr933

\begin{abstract}
Anabas testudineus (Anabantidae) is an important food fish in Southeast Asia. We analyzed the mitochondrial DNA control region sequence data to evaluate the genetic variability and population structure of this species. Sixty specimens were collected from four populations in Sumatra and two populations in Peninsular Malaysia. We found a very low level of genetic variability, with five of the six populations exhibiting total absence of genetic variation. Based on analysis of molecular variance, $84.72 \%$ of the total variation was among populations and $15.28 \%$ within populations. A geographical division based on $\mathrm{F}_{\mathrm{ST}}$ values indicated highly significant genetic differentiation
\end{abstract}


among populations from the four drainage systems: Aceh, Sumatra Utara, Pulau Pinang, and Terengganu ( $\mathrm{F}_{\mathrm{ST}}$ ranging from 0.633 to 1.000). No phylogeographic relationships among populations were detected, despite the generation of four distinct clades in a neighbor-joining phylogenetic tree.

Key words: Anabas testudineus; Climbing perch; Sundaland; Population genetics; Control region

\section{INTRODUCTION}

Anabas testudineus, locally known as puyu or climbing perch, is an indigenous tropical potamodromous fish that is widely distributed in Southeast Asia, South Asia and mainland China (Kottelat et al., 1993; Froese and Pauly, 2009). This obligatory air-gulping fish can be found in most drainage systems and is considered to be a hardy species since it can tolerate extremely hostile conditions (Atack, 2006). At present, it is one of the primary freshwater/ brackish water food and ornamental fish in this region. It is usually marketed alive fetching a price of around US $\$ 4 / \mathrm{kg}$.

The existing literature provides limited genetic information on population variation of A. testudineus. Sekino and Hara's (2000) study on genetic characteristics and relationships of $A$. testudineus populations in Thailand based on allozyme data showed three major stocks influenced by topographical features, mainly the river systems in Thailand. However, the population structure and demographic history of $A$. testudineus still remain largely unknown in this biodiversity-rich area of Sundaland. Furthermore, the taxonomic status is still the focus of further debate. Based on personal observation and reports by Kottelat et al. (1993), Rainboth (1996), Inger and Kong (2002), and Atack (2006), the morphological traits, i.e., color, body form and meristic data of the species, have been described as a variable. This suggests that there might be more than a single species of Anabas present in the region. In addition, as the species is also widely cultured, translocation is expected to be a common occurrence and may possibly result in disturbances of its natural genetic structures.

Considering these scenarios, the objective of this study was to determine the genetic variation of $A$. testudineus of four populations from Sumatera and two populations from Peninsular Malaysia by using the partial mtDNA control region (D-loop) sequence. This study will provide preliminary assessment of genetic diversity patterns of A. testudineus in this region for conservation, management and stock identification.

\section{MATERIAL AND METHODS}

\section{Sample acquisition and laboratory analysis}

Ten specimens of A. testudineus were collected from each population of i) four populations in Sumatera Island namely Sibreh, Lamreng and Tungkop in Aceh Province and Medan, and ii) two populations in Peninsular Malaysia namely Pulau Pinang (Northwest) and Terengganu (East) (Figure 1 and Table 1). Extraction of total DNA was 
performed using an AquaGenomic ${ }^{\mathrm{TM}}$ DNA isolation Kit (BioSyntech, Salt Lake City, UT, USA) following manufacturer specifications. A segment of the mtDNA control region was amplified using the primers L16473 (5'-CTA AAA GCA TCG GTC TTG TAA TCC-3') and H355 (5'-CCT GAA ATG AGG AAC CAG ATG-3'). Amplification was performed in an MJ PTC-200 Thermal Cycler (MJ Research, Waltham, MA, USA) on a 25.0- $\mu \mathrm{L}$ reaction mixture containing approximately $100 \mathrm{ng}$ template DNA, 1.0X PCR buffer, $2.8 \mathrm{mM}$ $\mathrm{MgCl}, 0.2 \mathrm{mM}$ dNTPs, $0.02 \mu \mathrm{M}$ each primer, $0.06 \mathrm{U}$ Taq DNA polymerase and making up the total with $\mathrm{ddH}_{2} \mathrm{O}$. Polymerase chain reaction (PCR) was performed with the following profile: initial denaturation at $94^{\circ} \mathrm{C}$ for 2 min followed by 30 cycles consisting of $94^{\circ} \mathrm{C}$ for $1 \mathrm{~min}, 56^{\circ} \mathrm{C}$ for $70 \mathrm{~s}, 72^{\circ} \mathrm{C}$ for $2 \mathrm{~min}$ and a final extension at $72^{\circ} \mathrm{C}$ for another 5 min. DNA amplification products were separated on $1.5 \%(\mathrm{w} / \mathrm{v})$ agarose gels for $30 \mathrm{~min}$ at $100 \mathrm{~V}$, stained with ethidium bromide and visualized under UV light. PCR products were subsequently purified using the Gel and PCR Clean-Up System (Promega, Madison, WI, USA) and sequenced using Big Dye Terminator v3.1 on an ABI3730XL Genetic Analyzer (Applied Biosystems, Foster City, CA, USA).

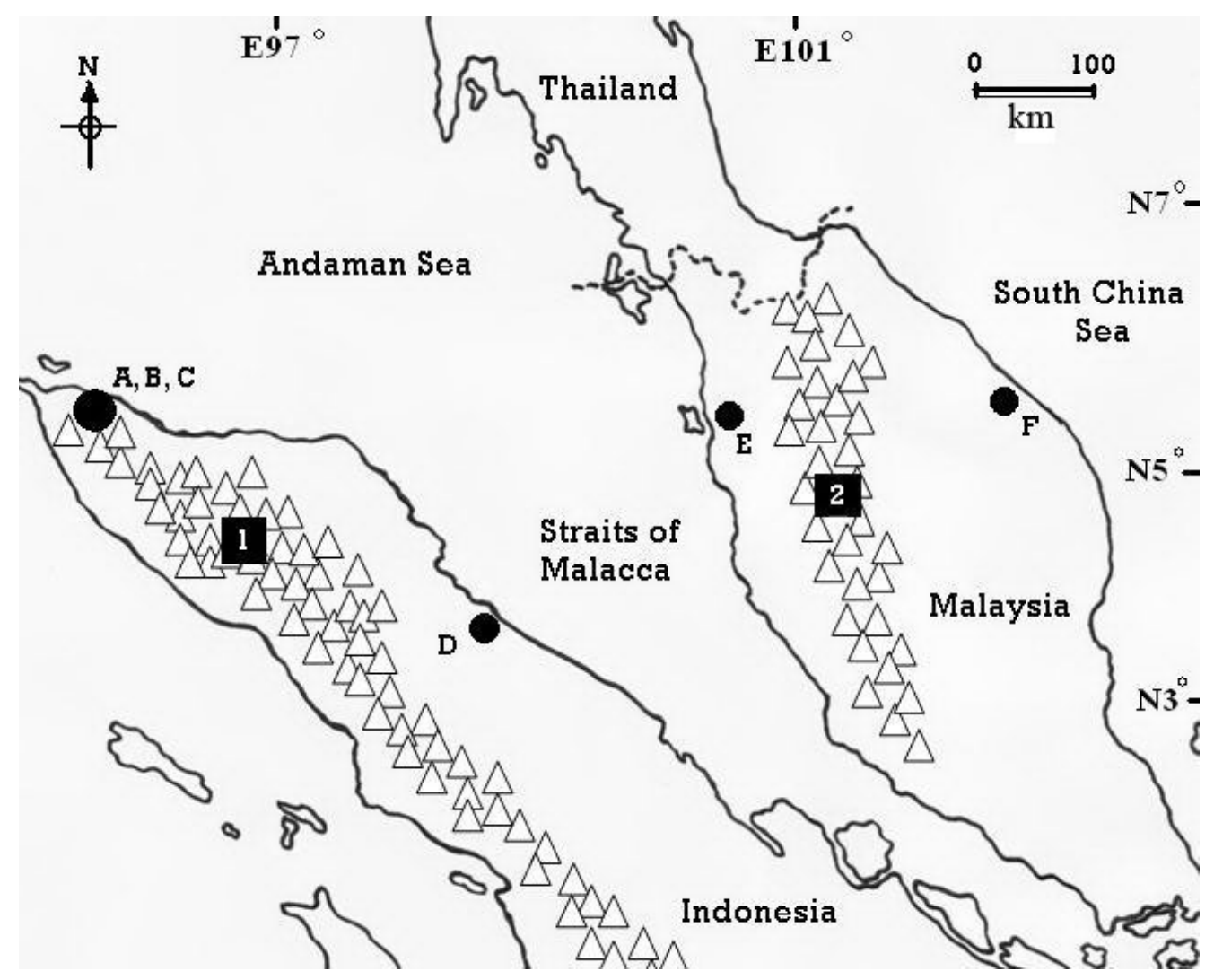

Figure 1. Sampling locations of six Anabas testudineus populations. Closed circles (followed by capital letters) represent the sampling sites: (A, B, C) Sibreh, Tungkop and Lamreng - Aceh; (D) Medan; (E) Pulau Pinang, and (F) Terengganu. Squares (with numbers) are significant geographical landmarks present in the region; (1) Barisan Mountain Range and (2) Titiwangsa Mountain Range. 


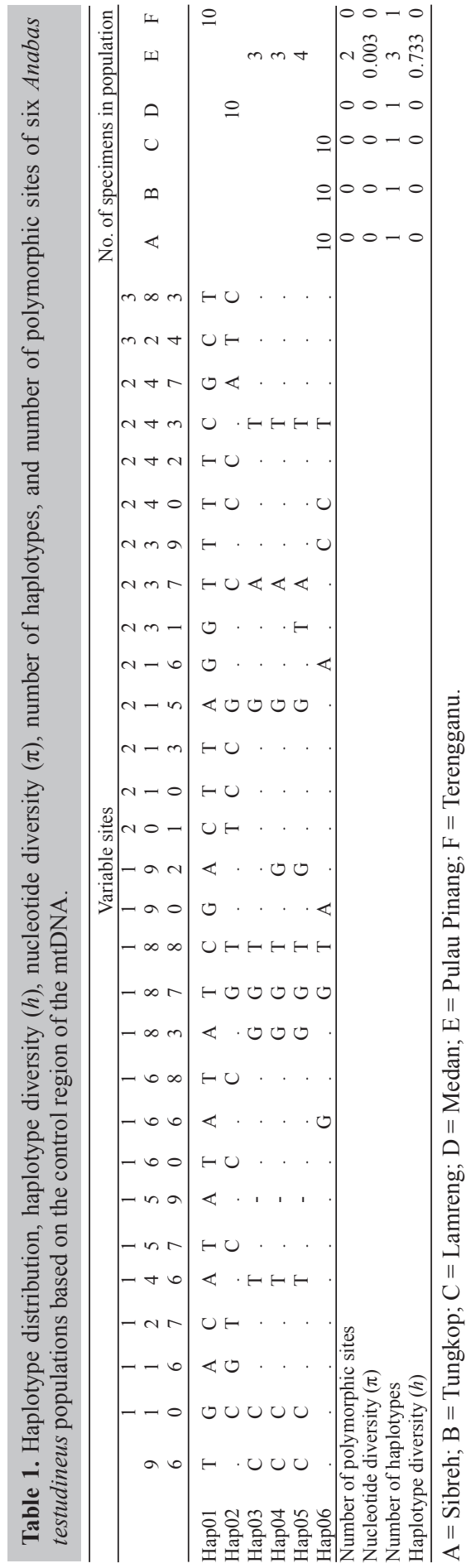




\section{Data analysis}

All sequences were viewed, edited and aligned using the MEGA 4.0 software (Tamura et al., 2007). DAMBE (Xia and Xie, 2001) was used to determine identical haplotypes in the aligned matrix. Haplotype diversity $(h)$, nucleotide diversity $(\pi)$ and other molecular diversity indices as well as population comparisons of pairwise $F$-statistics and analysis of molecular variation (AMOVA) were calculated using Arlequin version 3.1 (Schneider et al., 2000) to assess the genetic variability and population structuring. To correct for multiple comparisons, the sequential Bonferroni's correction was applied with a global significance level of 0.05 . A bootstrap (1000 replicates) neighbor-joining (NJ) tree was constructed based on the Kimura-2-parameter model (Kimura, 1980) to depict haplotype relationships using the MEGA 4.0 software.

\section{RESULTS}

A total of $403 \mathrm{bp}$ from the control region, aligned in sequences characterized by 29 parsimony informative sites [of which 23 were transitions (Ts), four transversions (Tv), single site each with both Ts and Tv and indels (insertions/deletions)] were generated. Only six unique haplotypes were observed. All sequences have been deposited in GenBank under accession numbers GU570698-GU570703. The mean total nucleotide composition was A = $35.4 \%, \mathrm{~T}=31.2 \%, \mathrm{C}=20.4 \%$, and $\mathrm{G}=13.0 \%$. Interestingly, five of the six populations (with the exception of Pulau Pinang) were monomorphic for a single haplotype, exhibiting absence of genetic variability. The only variable population, Pulau Pinang, showed $h$ : 0.733 and $\pi$ : 0.003 (Table 1). Furthermore, five of the haplotypes were unique to a specific population. Of these, one each was observed in Terengganu (Hap01) and Medan (Hap02) and three (Hap03, Hap04 and Hap05) in Pulau Pinang. The single remaining haplotype (Hap06) was the sole variant in all three populations of Aceh Province, i.e., Sibreh, Lamreng and Tungkop.

Nucleotide divergence between populations varied from 2.0\% (between Aceh populations in Sumatera and the Terengganu population in East Peninsular Malaysia) to 5.2\% (between Aceh and Medan populations, all Sumatera Island populations) (Table 2) with the overall average value being $2.9 \%$. $\mathrm{F}_{\mathrm{ST}}$ values (Table 2 ) indicated highly significant genetic differentiation among the four drainage systems: Aceh, Medan, Pulau Pinang, and Terengganu (with $\mathrm{F}_{\mathrm{ST}}$ values ranging from 0.633 to 1.000 ). This was strongly supported by the NJ phylogenetic tree, which divided the haplotypes into four discrete allopatric clusters, corresponding to the individual drainage system (Figure 2). However, as noted in the nucleotide divergence values, the differentiation was not correlated with geographical distance. AMOVA (data not

\begin{tabular}{|c|c|c|c|c|c|c|}
\hline & 1 & 2 & 3 & 4 & 5 & 6 \\
\hline 1 - Sibreh & - & 0.0 & 0.0 & 5.2 & 3.1 & 2.0 \\
\hline 2 - Lamreng & 0.000 & - & 0.0 & 5.2 & 3.1 & 2.0 \\
\hline 3 - Tungkop & 0.000 & 0.000 & - & 5.2 & 3.1 & 2.0 \\
\hline 4 - Medan & 1.000 & 1.000 & 1.000 & - & 4.9 & 4.7 \\
\hline 5 - Pulau Pinang & 0.633 & 0.633 & 0.633 & 0.633 & - & 2.5 \\
\hline 6 - Terengganu & 1.000 & 1.000 & 1.000 & 1.000 & 0.633 & - \\
\hline
\end{tabular}


shown) indicated that $84.72 \%$ of the total variation existed among populations and $15.28 \%$ within the population with a significant overall level of genetic structuring among samples $\left(\mathrm{F}_{\mathrm{ST}}=0.847 ; \mathrm{P}<0.001\right)$. The variation within the population was singularly contributed by variation in the Pulau Pinang population.

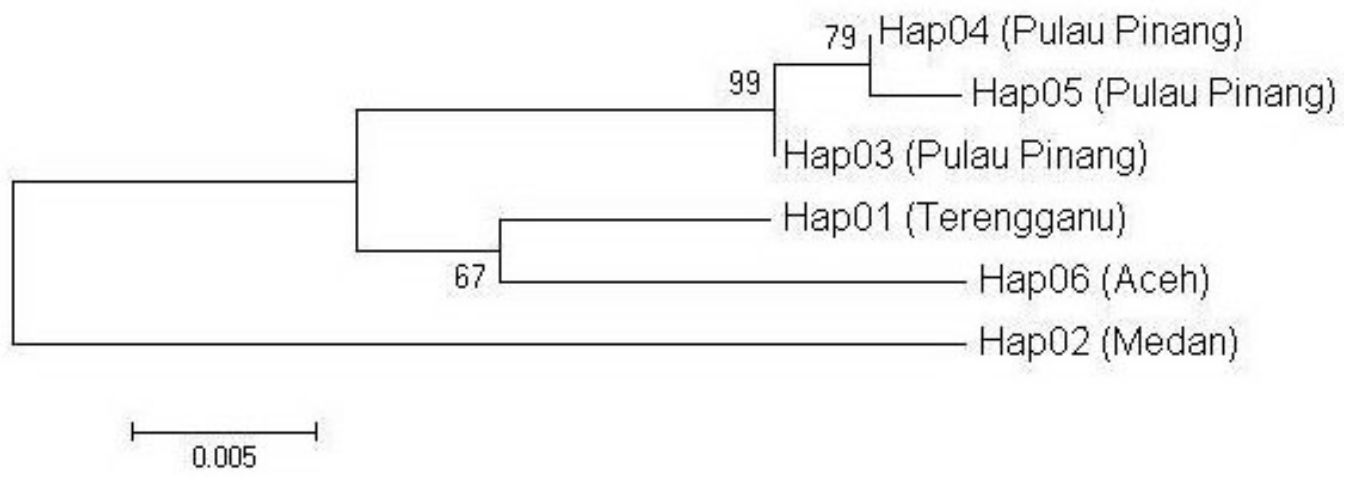

Figure 2. Neighbor-joining dendogram based on the Kimura 2-parameter distance model showing the control region haplotype relationships among six populations of Anabas testudineus. The numbers on branches indicate the bootstrap values based on 1000 replications.

\section{DISCUSSION}

The present investigation provided some initial insights into the genetic distribution of A. testudineus in the Sundaland. All values found in this study are in accordance with intraspecific comparisons for the control region in previous freshwater fish population studies, which ranged from 0 to $16.7 \%$ (Martins et al., 2003; Sun et al., 2004). Based on the limited data, it is deduced that only a single species of Anabas is present in this region. The total absence of genetic variability in all populations (except Pulau Pinang) could likely be explained by 'a single female origin' of each of these populations since mtDNA is maternally inherited (Avise, 1994). The specimens were collected in an agricultural area (rice field, sluggish irrigation canal and swamp) and the use of chemical stresses, i.e., pesticides and fertilizers, might also be a factor responsible for the selective sweep of the populations for the most favorable haplotype. Furthermore, the behavior of the A. testudineus, perhaps to some extent, contributed to this unexpected extremely low genetic variability pattern. The species has a tendency to congregate together in familiar shoals for some social reasons (Binoy and Thomas, 2004, 2006). This trait may lead to increased chances of the same female line being caught, raising the probability of inadequate sampling, thus accounting for the observed lack of genetic diversity. However, the observed genetic variation in the studied populations might also have been underestimated by the low sample sizes $(\mathrm{N}=10)$.

Based on the $\mathrm{F}_{\mathrm{ST}}$ values, significant differentiation was observed, except for populations within Aceh Province. Curiously, the divergence pattern did not detect any parallel relationship between the genetic and geographical distances based on the nucleotide divergence values or the NJ phylogenetic tree. The nucleotide divergence showed unexpected data as the lowest sequence distance $(2.0 \%)$ was among populations separated by a great expanse of land 
and sea (between Aceh and Terengganu). On the other hand, the comparison between populations on Sumatera Island showed the highest distance (between Aceh and Medan). What could be inferred from our limited data is that, by and large, natural gene flow is restricted, presumably by topographical barriers as shown by the overall uniqueness of the population haplotypes. For example, Pulau Pinang and Terengganu populations are separated by the Titiwangsa Mountain Range, which acts as an effective barrier to gene flow as had also been reported in previous studies on other species (Ruzainah, 2008; Norkarmila, 2009). However, where there is a possibility of migration gene flow may be high, as exemplified by the three Aceh populations of Sibreh, Tungkop and Lamreng, which shared the same haplotype through a common drainage system. This is in spite of the approximately 4 to $22 \mathrm{~km}$ land distances between these populations. The species is reported to have the ability to move at considerable distances over dry land (hence, climbing perch) towards water sources and can also undertake lateral migration in flood-plain areas (Rainboth, 1996; Froese and Pauly, 2009). This activity could act as a homogenizing agent of different gene pools whenever migration is possible. In addition, since this species is economically important and reportedly cultured across its native range (Rainboth, 1996), translocation may be common leading to alteration of the genetic structural pattern in the Aceh region. As a fish for food supply, stock enhancement or introgression of exogenous immigrants can lead to homogenization of previously structured populations. Another possibility is that the genetic closeness of the geographically distant populations of Terengganu and Aceh indicated a common origin as it is highly unlikely that translocation between the two areas had occurred. Thus, the present genetic pattern may be a result of the interplay between a common origin, possible migration events (both natural and by human intervention), followed by isolation, as well as the clustering behavior of this species. Finally, the small sample size and number of populations used in this study may be insufficient to provide an accurate estimate of the phylogeographic and genetic pattern of the species.

In conclusion, this study provided valuable initial genetic data in making inference of the genetic structure of $A$. testudineus in the Sundaland. The study revealed remarkably low genetic variation and four significant stocks of $A$. testudienus from different river drainages, although, without clear phylogeographic relationships among populations. However, these inferences are preliminary. Further analyses with more sampling effort (population, sample size for each population and temporal replicates) and more efficient molecular markers (i.e., highly variable marker-microsatellite) are needed to provide a clear understanding of the genetic distribution and population dynamics of the A. testudineus populations in the Sundaland region.

\section{ACKNOWLEDGMENTS}

Research supported by the Ministry of Science, Technology \& Innovation (MOSTI), Malaysia (\#304/PBIOLOGI/6521033/U128). The authors are indebted to colleagues from Universiti Sains Malaysia, Penang and Syiah Kuala University, Aceh, for their help in sampling, suggestions and technical assistance for this study.

\section{REFERENCES}

Atack K (2006). A Field Guide to the Fishes of Kuching Rivers, Sarawak, Malaysian Borneo. Natural History Publications (Borneo), Kota Kinabalu.

Avise JC (1994). Molecular Markers, Natural History and Evolution. Chapman and Hall, New York. 
Binoy VV and Thomas KJ (2004). The climbing perch (Anabas testudineus Bloch), a freshwater fish, prefers larger unfamiliar shoals to smaller familiar shoals. Curr. Sci. 86: 207-211.

Binoy VV and Thomas KJ (2006). Climbing perch (Anabas testudineus Bloch) recognizes members of familiar shoals. Curr. Sci. 90: 288-289.

Froese R and Pauly D (2009). FishBase. World Wide Web Electronic Publication. Available at [http://www.fishbase.org/ search.php]. Accessed November, 2009.

Inger RF and Kong CP (2002). The Fresh-Water Fishes of North Borneo. Natural History Publications (Borneo), Kota Kinabalu.

Kimura M (1980). A simple method for estimating evolutionary rates of base substitutions through comparative studies of nucleotide sequences. J. Mol. Evol. 16: 111-120.

Kottelat M, Whitten EJ, Kartikasari SN and Wirjoatmodjo S (1993). Freshwater Fisheries of Western Indonesia and Sulawesi. Periplus Edition Ltd., Singapore.

Martins C, Wasko AP, Oliveira C and Foresti F (2003). Mitochondrial DNA variation in wild populations of Leporinus elongatus from the Paraná River basin. Genet. Mol. Biol. 26: 33-38.

Norkarmila D (2009). Mophometric and Genetic Variability of River Terrapin (Batagur baska) and Painted Terrapin (Batagur borneoensis). Master's thesis, School of Biological Sciences, USM, Pulau Pinang.

Rainboth WJ (1996). Fishes of the Cambodian Mekong. FAO Species Identification Field Guide for Fishery Purposes. Food and Agriculture Organization of the United Nations (FAO), Rome.

Ruzainah A (2008). Molecular Genetic Studies of Marble Goby Oxyeleotris marmoratus (Bleeker, 1852) in Malaysia. Doctoral thesis, School of Biological Sciences, USM, Pulau Pinang.

Schneider S, Roessli D and Excofiioer L (2000). Arlequin Ver. 2000: A Software for Population Genetic Data Analysis. Version 1.1. Genetics and Biometry Laboratory, University of Geneva, Geneva.

Sekino M and Hara M (2000). Genetic characteristics and relationships of climbing perch Anabas testudineus populations in Thailand. Fish. Sci. 66: 840-845.

Sun Y, Liu S, Zhao G, He S, et al. (2004). Genetic structure of Chinese sucker population Myxocyprinus asiaticus in the Yangtze River based on mitochondrial DNA marker. Fish. Sci. 70: 412-420.

Tamura K, Dudley J, Nei M and Kumar S (2007). MEGA4: molecular evolutionary genetics analysis (MEGA) software version 4.0. Mol. Biol. Evol. 24: 1596-1599.

Xia X and Xie Z (2001). DAMBE: software package for data analysis in molecular biology and evolution. J. Hered. 92: 371-373. 